\title{
BMJ Global Health The evolving picture of SARS-CoV-2 and COVID-19 in children: critical knowledge gaps
}

\author{
Priscilla Idele (D) , ${ }^{1}$ David Anthony, ${ }^{2}$ Danzhen You, ${ }^{3}$ Chewe Luo, ${ }^{4}$ Lynne Mofenson ${ }^{5}$
}

To cite: Idele P, Anthony D, You $\mathrm{D}$, et al. The evolving picture of SARS-CoV-2 and COVID-19 in children: critical knowledge gaps. BMJ Global Health 2020;5:e003454. doi:10.1136/ bmjgh-2020-003454

Handling editor Seye Abimbola

- Additional material is published online only. To view, please visit the journal online (http://dx.doi.org/10.1136/ bmjgh-2020-003454)

Received 15 July 2020 Revised 28 July 2020 Accepted 29 July 2020

Check for updates

(c) Author(s) (or their employer(s)) 2020. Re-use permitted under CC BY-NC. No commercial re-use. See rights and permissions. Published by BMJ.

${ }^{1}$ Office of Research, UNICEF New York, New York, USA ${ }^{2}$ Office of Research, UNICEF, Florence, Toscana, Italy ${ }^{3}$ Data \& Analytics, UNICEF, New York, New York, USA ${ }^{4}$ HIV/AIDS Section, UNICEF, New York, New York, USA ${ }^{5}$ Research Programme, Elizabeth Glaser Pediatric AIDS Foundation, Washington DC, District of Columbia, USA

Correspondence to Dr Priscilla Idele; pidele@unicef.org

\section{INTRODUCTION}

In December 2019, a novel coronavirus, SARS-CoV-2, emerged in Wuhan City, China, causing a cluster of cases of severe pneumonia (COVID-19), and becoming a global pandemic. Individuals of all ages are susceptible to SARS-CoV-2, but older age and underlying comorbidities are known to be associated with increased risk of disease severity and mortality. However, despite the rapidly increasing amount of data on SARS-CoV-2 infection and COVID19, data on how SARS-CoV-2 affects children and adolescents remain limited and conflicting, with an increased spectrum of disease manifestations emerging (eg, multisystem inflammatory syndrome). Critical research needs have emerged with important public policy implications.

\section{LACK OF DATA HINDERS A FULL EPIDEMIOLOGIC ASSESSMENT OF COVID-19/SARS-COV-2 INFECTION IN CHILDREN}

In initial data from China, children had significantly lower rates and severity of COVID-19 than adults; $2 \%$ of cases were aged $0-19$ years, $0.9 \%<10$ years, with no child deaths. ${ }^{1}$ Children continue to constitute a low proportion of those diagnosed with COVID-19 in reports for Europe and USA. However, the exact prevalence of COVID-19 in children is difficult to ascertain, as there is no single place to obtain country comparable age-related data. Global data are not readily available disaggregated by age, and country data likewise lack age breakdown or may only provide data for those $<20$ years. Data on the proportional age breakdown between birth and 19 years are limited, and existing reports often use different and overlapping age categories.
Summary box

The initial impression that paediatric infection is uncommon and generally mild has been replaced by a more nuanced understanding of infectious manifestations in children across countries and by income group, with recognition of a widening disease spectrum.

- Critical knowledge gaps remain that have significant public policy and programme implications.

- Insufficient age and race/ethnicity disaggregated data are hindering efforts to assess fully the prevalence of SARS-CoV-2 infection and COVID-19 in children and the role of children in transmission.

- Potential biologic differences in susceptibility to infection and transmissibility between children and adults need to be explored.

- Determination of mother-to-child SARS-CoV-2 transmission requires appropriate samples obtained with proper timing, lacking in most studies.

- Predictors of disease progression and morbidity and mortality in children need to be determined, particularly as the pandemic moves to low-income and middle-income countries.

- The full spectrum of SARS-CoV-2 infection in children remains to be defined, and surveillance for and investigation of the pathogenesis of postinfectious sequelae, such as multisystem inflammatory syndrome, are vital.

Data from various country-specific online surveillance databases, dashboards and reports indicate that there is a broad spectrum of COVID-19 burden among those $<20$ years as a share of national caseloads, ranging from 23\% in Paraguay to just $1 \%$ in Spain (figure 1 and online supplemental table 1 in Annex). Accurate, agedisaggregated data are critical to better understand the geographic variations and age distribution in paediatric cases.

In adults, a higher proportion of COVID-19 and mortality has been reported among black and ethnic minorities compared with Caucasians in the USA and 


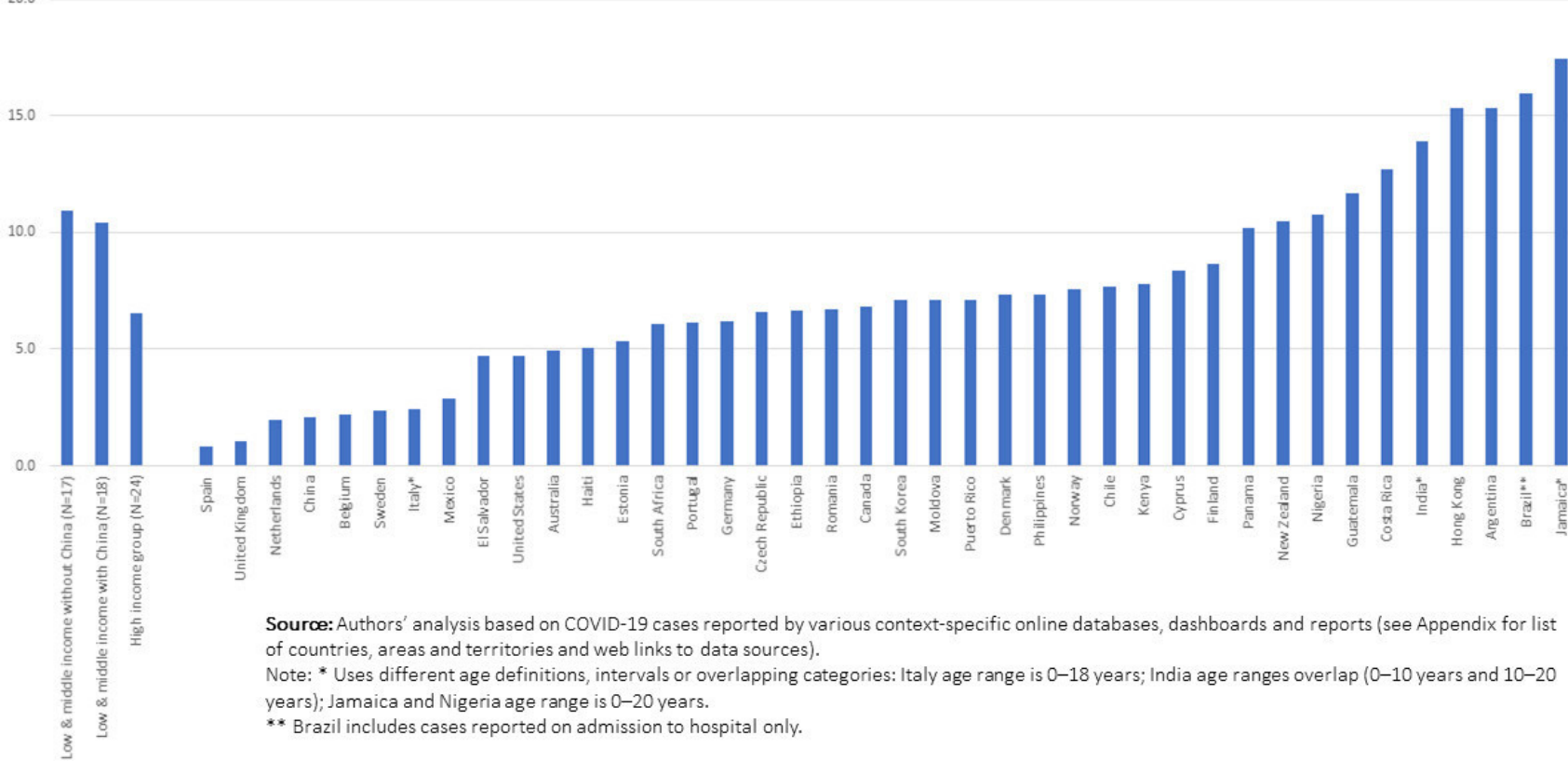

Figure 1 COVID-19 infections among children and adolescents (under 20s) as a share of total national caseloads varies widely among countries and by income group.

$\mathrm{UK}^{2}$ There are limited data on COVID-19 and race/ ethnicity in children, since it is not reported in most paediatric studies. Several reports from the USA and UK suggest minority race/ethnicity is significantly associated with SARS-CoV-2 infection and disease in children. ${ }^{3}{ }^{4}$ While these data may represent social determinants of infection among minority populations, the disproportionate representation of minority and vulnerable groups is concerning as the pandemic is emerging in Africa and Asia. At a minimum, studies of SARS-CoV-2 in children should report disaggregated data by race/ethnicity and age.

\section{TRANSMISSION TO CHILDREN: ARE CHILDREN LESS SUSCEPTIBLE THAN ADULTS TO SARS-COV-2?}

The true incidence of paediatric SARS-CoV-2 infection is unknown. This is due to SARS-CoV-2 screening being predominantly symptom-based, and surveillance data primarily reflecting individuals diagnosed with COVID-19. It is unclear whether the lower reported incidence of paediatric infection is because children are less likely to be tested because they have atypical/milder symptoms than adults; less likely to be exposed to infected individuals given mitigation measures such as school closures; or there is lower biologic susceptibility.

Viner and colleagues conducted a systematic review exploring the issue of susceptibility in publications reporting contact investigations following an index COVID-19 case and limited population-based surveillance studies, identifying 18 relevant publications. ${ }^{5}$ Meta-analysis of nine contact-tracing studies found children/adolescents aged $<20$ years had $56 \%$ lower risk of infection after index exposure than adults $>20$ years (pooled OR 0.44 , 95\% CI 0.29 0.69 ), with substantial between-study heterogeneity. The authors noted there were insufficient data to do analyses separating younger from older children because few studies reported sufficient age disaggregation. Although some population-based studies are emerging, their findings so far are inconsistent, and most include only small numbers of children and adolescents. Therefore, there are currently insufficient data to draw definitive conclusions regarding SARS-CoV-2 infection incidence in children.

Susceptibility to SARS-CoV-2 may be related to host cell expression of the viral receptor, angiotensin-converting enzyme-2 (ACE-2) and protease-cleaving enzymes such as transmembrane serine protease 2 (TMPRSS2), which facilitates viral-cell membrane fusion. A recent study evaluated ACE-2 gene expression in nasal epithelial specimens from 305 individuals aged 4-60 years collected in a study of patients with asthma. ${ }^{6}$ Children aged 4-9 years had significantly lower expression of ACE-2 in the nasal epithelium compared with older children 10-17 years, young adults $18-24$ years and adults $>25$ years. A separate study evaluated several public gene-expression datasets and reported that gene expression for ACE-2 and TMPRSS2 was lower in children compared with adults in nasal and bronchial tissue. ${ }^{7}$ If confirmed, these findings 
could account for potential decreased susceptibility to SARS-CoV-2 acquisition and/or replication in children.

\section{TRANSMISSION FROM CHILDREN TO ADULTS AND OTHER CHILDREN WITHIN SCHOOLS: IMPORTANCE REMAINS UNDEFINED AND FURTHER INVESTIGATION IS REQUIRED}

Data are conflicting regarding risk of SARS-CoV-2 transmission from children to adults, and to other children. While children are more likely to have mild or asymptomatic disease, transmission has been demonstrated to occur from asymptomatic as well as symptomatic individuals, including children within family clusters. ${ }^{8}$ There are only limited comparative studies of viral load in respiratory secretions in children compared with adults, and the correlation between SARS-CoV-2 real-time polymerase chain reaction (rtPCR) viral load and transmissibility, or what constitutes an infectious SARS-CoV-2 inoculum, is unknown. ${ }^{10}$ A higher proportion of children have SARS-CoV-2 faecal shedding than adults, and for more prolonged periods; it is unclear whether faecal rtPCR viral detection represents active viral replication or residual non-infectious viral genomic material and whether there is potential for faecal-oral viral transmission. ${ }^{11}$

Child-to-adult transmission has been documented in small case reports. ${ }^{9}$ However, other reports suggest children have not played a substantive role in household SARS-CoV-2 transmission. ${ }^{12}$ There are limited data on school-related contact tracing; two studies from France and Australia suggest that children have not played a significant role in school SARS-CoV-2 transmission. ${ }^{13} 14$ Further evaluation is needed to determine whether children (and schools) will play a more substantive role once mitigation measures are eased, and whether children are less infectious than adults.

\section{MOTHER-TO-CHILD TRANSMISSION OF SARS-COV-2}

For in utero transmission, the pathogen must be present in blood and be able to cross the placenta and infect the fetus. Viraemia secondary to SARS-CoV-2 appears rare. ${ }^{15}$ In the few cases in which viraemia occurs, allowing the virus to reach the placenta, it may be possible to cross the placenta and infect the fetus, as the ACE-2 receptor has been identified in both placental and fetal tissues. ${ }^{16}$ While SARS-CoV-2 infection has been reported to be detected in a small number of infants born to pregnant women with COVID-19, determination of in utero infection is complex, and requires sampling of appropriate tissues or fluids near the time of birth. ${ }^{17}$ Most studies have not collected appropriate samples with proper timing

The University of Birmingham is conducting a 'living systematic review' of publications related to SARS-CoV-2/ COVID-19 in pregnancy and effect on pregnancy and infant outcomes. ${ }^{18}$ As of 16 June 2020, 52/869 infants born to women with COVID-19 had SARS-CoV-2 detected following exposure to the virus. Of these, only eight had a positive nasopharyngeal swab collected within 12 hours after birth; none had virus detected in cord/neonatal blood, amniotic fluid or the placenta. ${ }^{19-21}$ There have been a small number of reports of SARS-CoV-2 detection in cord blood, placenta and breast milk, or SARS-CoV-2 IgM antibody detection in neonatal blood; in all instances, the infants had negative nasopharyngeal tests, no symptoms and/or IgM turned negative by 12-28 days. Thus, from the available data, while mother-to-child transmission of SARS-CoV-2 is possible, it has not yet been confirmed.

\section{CLINICAL ASPECTS OF SARS-COV-2 IN CHILDREN: MOSTLY MILDER OR NO SYMPTOMS COMPARED WITH ADULTS}

Children and young adults appear to have milder COVID-19 than adults. In a systematic review of 62 papers reporting on COVID-19 in 1780 children, primarily from Italy (44\%), USA (34\%) and China (18\%), children showed mainly mild (42\%, upper respiratory symptoms without pneumonia) and moderate $(39 \%$, pneumonia without complications) signs of infection; $15 \%$ were asymptomatic. ${ }^{22}$ Severe symptoms and critical disease (need for invasive ventilation, shock or multiorgan failure) were reported in only $2 \%$ and $0.6 \%$, respectively, and overall mortality was uncommon, $0.8 \%$. A higher proportion of neonates/infants age $<3$ months had severe illness (12\%) compared with older children. In contrast, in the Chinese Center for Disease Control and Prevention report on 44672 COVID-19 cases in China (included 965 children $<19$ years, $2.2 \%$ ), $1 \%$ had asymptomatic infection, $81 \%$ mild to moderate (nonpneumonia and pneumonia combined), $14 \%$ severe and $5 \%$ critical disease, with $2.3 \%$ mortality. ${ }^{23}$ It is important to note that most studies have focused on symptomatic or hospitalised patients, and the true spectrum of disease among adults and children in the overall population remains to be defined.

While symptoms of COVID-19 in children were similar to those of adults, with fever, cough and sore throat being the most common, children had lower rates of these symptoms compared with adults (figure 2); dyspnoea was uncommon in children. ${ }^{22} 24$

\section{CLINICAL ASPECTS OF SARS-COV-2 IN CHILDREN: SEVERE DISEASE CAN OCCUR}

Despite generally milder disease than adults, children can be extremely ill and when requiring intensive care, have elevated mortality. Among 92 children admitted to paediatric intensive care units (PICUs) in North America, France, South America, Europe and USA, 33\%-47\% required invasive ventilation and mortality ranged from $6 \%$ to $18 \% .^{25-27}$

While data on chronology of complications and predictors of mortality are available in adults, there are currently limited data in children. Pre-existing health conditions, while less frequent in children than adults with COVID-19, were observed in $61 \%$ of hospitalised children in the USA, most commonly obesity, asthma 


\section{Disease Symptoms in 1,780 Children and Adolescents 0-18 Years with SARS-CoV-2 Infection}

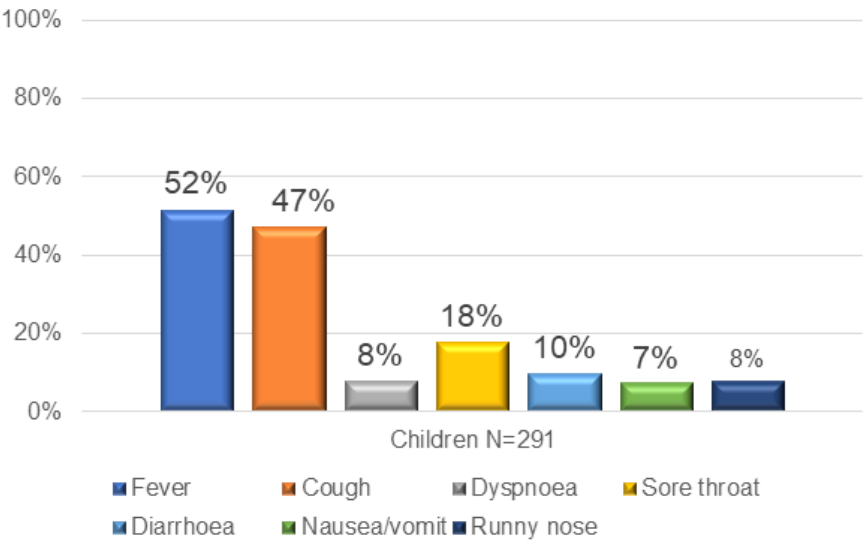

Systematic Review - Liguoro I et al. Eur J Pediatr. 2020 May 18
Disease Symptoms in 10,944 Adults 18-64 Years in US with SARS-CoV-2 Infection

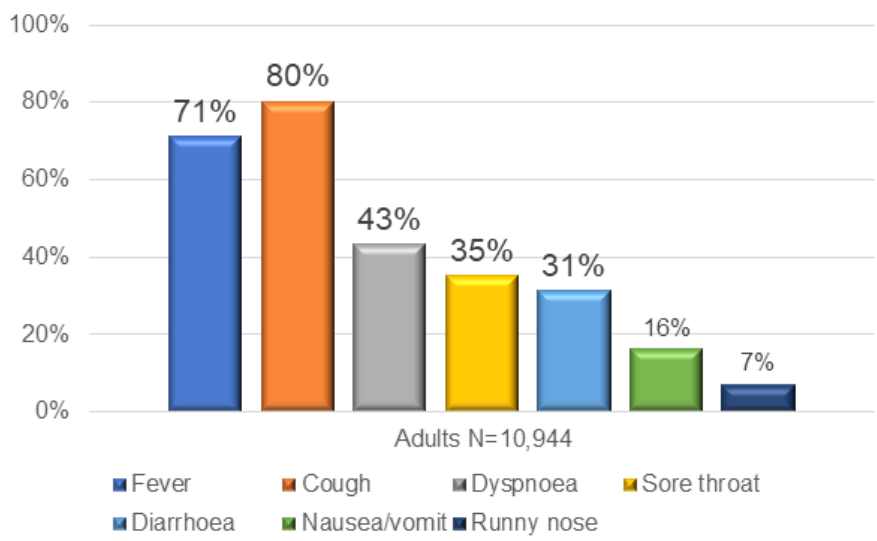

CDC COVID-19 Response Team. MMWR 2020 Apr 6;69 (US data)

Figure 2 Disease symptoms of SARS-CoV-2 infection in children differ markedly from those in adults.

and neurologic disease. ${ }^{24}$ Children admitted to the PICU have high comorbidity rates $(70 \%-83 \%)$; however, of the nine reported deaths in these studies, three were in children without any comorbidity. ${ }^{25-27}$

Which comorbidities are associated with elevated mortality in children remain to be defined. Several studies report pre-existing asthma was not different between children testing positive or negative for SARS-CoV-2 nor associated with hospitalisation risk. ${ }^{32}$ However, obesity has been a consistent risk factor for severe disease in both adults and children. ${ }^{29}$ It is important to note that the interaction of SARS-CoV-2/COVID-19 with comorbidities commonly seen in low-income and middle-income countries, such as malnutrition, HIV and other infectious conditions such as tuberculosis and malaria, remains undefined. Preliminary data from South Africa suggest higher mortality due to COVID-19 in HIV-infected adults; there are no data available for children. ${ }^{30}$

\section{THE EVOLVING SPECTRUM OF SARS-COV-2 IN CHILDREN: FULL EXTENT OF PAEDIATRIC DISEASE IN CHILDREN REMAINS TO BE ELUCIDATED}

In mid-late April 2020, reports from Western Europe identified a new febrile paediatric entity termed multisystem inflammatory syndrome temporally associated with SARS-CoV-2 infection, consisting of systemic hyperinflammation, multiorgan involvement, gastrointestinal symptoms, Kawasaki disease-like features, prominent cardiogenic shock and rarely death. ${ }^{31}$ Most children had either a respiratory sample positive for SARS-CoV-2 or IgM and/or IgG SARS-CoV-2 antibody, although they may not have had symptoms of infection. This syndrome may be a postinfectious inflammatory process precipitated by prior SARS-CoV-2 infection and immune complexmediated. Multiple similar case series from the USA, Italy, UK and France have been published. These data indicate a widening spectrum of SARS-CoV-2-related disease in children, ranging from asymptomatic or mild infection; persistent fever with inflammation; postinfection Kawasaki disease-like syndrome; and rarely, the paediatric inflammatory multisystem syndrome. The potential for such postinfectious sequelae, and geographic and racial/ ethnic differences, must be factored in considering the burden of SARS-CoV-2 infection in children.

\section{CONCLUSION}

There is much remaining to be learnt about SARS-CoV-2 in children. The initial impression that paediatric infection is uncommon and generally mild has been replaced by a more nuanced understanding of infectious manifestations in children across countries and by income group, with recognition of a widening disease spectrum. Critical knowledge gaps remain that have significant public policy and programme implications. For example, if children are less susceptible to infection and/or less likely to transmit, the effectiveness of school closures to reduce viral spread may be limited. Long-term effects will need to be evaluated to find whether mother-to-child viral transmission occurs. As the spectrum of disease in children becomes better elucidated, it will be important to understand geographic and racial/ethnic differences, particularly as the pandemic moves to low-income settings, where comorbidities and other vulnerabilities are more frequent among children.

Twitter Priscilla Idele @Priscillaldele

Contributors $\mathrm{PI}, \mathrm{DA}$ and LM conceptualised the manuscript. LM drafted the paper. $\mathrm{PI}, \mathrm{DA}, \mathrm{CL}$ and DY contributed to revisions. $\mathrm{Pl}$ is the guarantor of the article. $\mathrm{Pl}$ is a demographer and public health expert with more than three decades in research, monitoring and evaluation of health and HIV/AIDS programmes and serves as Deputy Director UNICEF Office of Research-Innocenti. DA is an economist with experience in managerial and strategy development, partnerships and engagement in setting policy agendas and serves as Chief, Strategy, Planning and Convening UNICEF Office of Research-Innocenti. DY is a demographer who serves as Senior Adviser Statistics and Monitoring at UNICEF and co-ordinator of the UN InterAgency Group for Child Mortality Estimation. CL is a paediatrician and Tropical 
Health Specialist with more than four decades of clinical paediatrics, research and programming and serves as Associate Director of Programmes and Chief, HIV/ AIDS Section at UNICEF. LM is a paediatric infectious disease specialist with almost three decades of research experience in maternal and paediatric HIV infection and serves as Senior HIV Technical Advisor to Research Program at the Elizabeth Glaser Paediatric AIDS Foundation. Peer reviewed journal articles and relevant data from various country-specific online surveillance databases, dashboards and reports were assessed.

Funding The authors have not declared a specific grant for this research from any funding agency in the public, commercial or not-for-profit sectors.

Competing interests None declared.

Patient and public involvement Patients and/or the public were not involved in the design, or conduct, or reporting or dissemination plans of this research.

Patient consent for publication Not required.

Provenance and peer review Not commissioned; externally peer reviewed.

Data availability statement All data relevant to this study are included in the article and supplement 1.

Open access This is an open access article distributed in accordance with the Creative Commons Attribution Non Commercial (CC BY-NC 4.0) license, which permits others to distribute, remix, adapt, build upon this work non-commercially, and license their derivative works on different terms, provided the original work is properly cited, appropriate credit is given, any changes made indicated, and the use is non-commercial. See: http://creativecommons.org/licenses/by-nc/4.0/.

ORCID iD

Priscilla Idele http://orcid.org/0000-0002-0261-7755

\section{REFERENCES}

1 Epidemiology Working Group for NCIP Epidemic Response, Chinese Center for Disease Control and Prevention. [The epidemiological characteristics of an outbreak of 2019 novel coronavirus diseases (COVID-19) in China]. Zhonghua Liu Xing Bing Xue Za Zhi 2020;41:145-51.

2 Khunti K, Singh AK, Pareek M, et al. Is ethnicity linked to incidence or outcomes of covid-19? BMJ 2020;369:m1548.

3 Bandi S, Nevid MZ, Mahdavinia M. African American children are at higher risk of COVID-19 infection. Pediatr Allergy Immunol 2020. doi:10.1111/pai.13298. [Epub ahead of print: 29 May 2020]

4 Harman K, Verma A, Cook J, et al. Ethnicity and COVID-19 in children with co-morbidities. Lancet Child Adolesc Health 2020;4 July 7:e24-5.

5 Viner RM, Mytton OT, Bonell C, et al. Susceptibility to SARS-CoV-2 infection amongst children and adolescents compared with adults: a systematic review and meta-analysis. MedRxiv 2020. [Epub ahead of print: 24 May 2020].

6 Bunyavanich S, Do A, Vicencio A. Nasal gene expression of angiotensin-converting enzyme 2 in children and adults. JAMA 2020;323 (23. doi:10.1001/jama.2020.8707. [Epub ahead of print: 20 May 2020].

7 Saheb Sharif-Askari N, Saheb Sharif-Askari F, Alabed M, et al. Airways expression of SARS-CoV-2 receptor, ACE2, and TMPRSS2 is lower in children than adults and increases with smoking and COPD. Mol Ther Methods Clin Dev 2020;18:1-6.

8 Bai Y, Yao L, Wei T, et al. Presumed asymptomatic carrier transmission of COVID-19. JAMA 2020;323:1406-7.

9 Cai J, Xu J, Lin D, et al. A case series of children with 2019 nove coronavirus infection: clinical and epidemiological features. Clin Infect Dis 2020. doi:10.1093/cid/ciaa198. [Epub ahead of print: 28 Feb 2020].

10 Widders A, Broom A, Broom J. SARS-CoV-2: the viral shedding vs infectivity dilemma. Infect Dis Health 2020;25:210-5.
11 Santos VS, Gurgel RQ, Cuevas LE, et al. Prolonged fecal shedding of SARS-CoV-2 in pediatric patients: a quantitative evidence synthesis. J Pediatr Gastroenterol Nutr 2020;71:150-2.

12 Posfay-Barbe KM, Wagner N, Gauthey M, et al. COVID-19 in children and the dynamics of infection in families. Pediatrics 2020;146. doi:10.1542/peds.2020-1576. [Epub ahead of print: 26 May 2020].

13 Danis K, Epaulard O, Bénet T, et al. Cluster of coronavirus disease 2019 (COVID-19) in the French Alps, February 2020. Clin Infect Dis 2020;71:825-32.

14 Macartney K, Quinn HE, Pillsbury AJ, et al. Transmission of SARSCoV-2 in Australian educational settings: a prospective cohort study. Lancet Child Adolesc Health 2020;20. doi:10.1016/S23524642(20)30251-0. [Epub ahead of print: 03 Aug 2020].

15 Wang W, Xu Y, Gao R, et al. Detection of SARS-CoV-2 in different types of clinical specimens. JAMA 2020;323:1843-4.

16 Li M, Chen L, Zhang J, et al. The SARS-CoV-2 receptor ACE2 expression of Maternal-Fetal interface and fetal organs by single-cell transcriptome study. PLoS One 2020;15:e020295.

17 Blumberg DA, Underwood MA, Hedriana HL, et al. Vertical transmission of SARS-CoV-2: what is the optimal definition? Am J Perinatol 2020;37:769-72.

18 University of Birmingham. COVID-19 in pregnancy (PregCOV19LSR). Available: https://www.birmingham.ac.uk/research/whocollaborating-centre/pregcov/about/prevalence.aspx [Accessed 16 Jun 2020].

19 Li M, Xu M, Zhan W, et al. Report of the first cases of mother and infant infections with 2019 novel coronavirus in Xinyang City Henan Province. Chin J Infect Dis 2020.

20 Knight M, Bunch K, Vousden N, et al. Characteristics and outcomes of pregnant women admitted to hospital with confirmed SARSCoV-2 infection in UK: national population based cohort study. BMJ 2020;369:m2107.

21 Carosso A, Cosma S, Borella F, et al. Pre-labor anorectal swab for SARS-CoV-2 in COVID-19 pregnant patients: is it time to think about it? Eur J Obstet Gynecol Reprod Biol 2020;249:98-9.

22 Liguoro I, Pilotto C, Bonanni M, et al. SARS-COV-2 infection in children and newborns: a systematic review. Eur J Pediatr 2020;179:1029-46.

23 Wu Z, McGoogan JM. Characteristics of and important lessons from the coronavirus disease 2019 (COVID-19) outbreak in China: summary of a report of 72314 cases from the Chinese center for disease control and prevention. JAMA 2020. [Epub ahead of print: 24 Feb 2020]

24 CDC COVID-19 Response Team. Coronavirus Disease 2019 in Children - United States, February 12-April 2, 2020. MMWR Morb Mortal Wkly Rep 2020;69:422-6.

25 Shekerdemian LS, Mahmood NR, Wolfe KK, et al. Characteristics and outcomes of children with coronavirus disease 2019 (COVID-19) infection admitted to US and Canadian pediatric intensive care units. JAMA Pediatr 2020. doi:10.1001/jamapediatrics.2020.1948. [Epub ahead of print: 11 May 2020].

26 Oualha M, Bendavid M, Berteloot $L$, et al. Severe and fatal forms of COVID-19 in children. Arch Pediatr 2020;27:235-8.

27 González-Dambrauskas S, Vásquez-Hoyos P, Camporesi A, et al. Pediatric critical care and COVID-19. Pediatrics 2020;9:e20201766.

28 DeBiasi RL, Song X, Delaney M, et al. Severe coronavirus Disease-2019 in children and young adults in the Washington, DC, metropolitan region. J Pediatr 2020;223:199-203.

29 Zachariah P, Johnson CL, Halabi KC, et al. Epidemiology, clinical features, and disease severity in patients with coronavirus disease 2019 (COVID-19) in a children's hospital in New York City, New York. JAMA Pediatr 2020:e202430.

30 Nordling L. HIV and TB increase death risk from COVID-19, study finds - but not by much. Available: https://www.sciencemag.org/ news/2020/06/hiv-and-tb-increase-death-risk-covid-19-study-findsnot-much [Accessed 16 Jun 2020].

31 Godfred-Cato S, Bryant B, Leung J, et al. COVID-19-associated multisystem inflammatory syndrome in children - United States, March-July 2020. MMWR Morb Mortal Wkly Rep 2020;69:1074-80. 